\title{
A systematic review of counterfeit and substandard medicines in field quality surveys
}

This article was published in the following Dove Press journal:

Integrated Pharmacy Research and Practice

29 September 2014

Number of times this article has been viewed

\author{
Abdulaziz Fahad Abdulaziz \\ Alghannam \\ Zoe Aslanpour \\ Sara Evans \\ Fabrizio Schifano \\ Department of Pharmacy, University \\ of Hertfordshire, Hatfield, \\ Hertfordshire, United Kingdom
}

Correspondence: Abdulaziz Fahad Abdulaziz Alghannam

Department of Pharmacy, School of Life and Medical Sciences, University of Hertfordshire, College Lane, Hatfield ALI0 9AB, United Kingdom

Tel +44 I707 284563

Fax +44 I707 284II 5

Email pharmafg@gmail.com
Objectives: Counterfeit and substandard medicines pose a great threat to public health and the economy worldwide. Reports suggest their prevalence is increasing and can no longer be ignored. A detailed account on the current nature of the problem and identification of knowledge limitations in terms of geographical location, medicine classes, and type of medicine analysis performed is not available. Our objective was to systematically review articles that have reported investigations of counterfeit and substandard medicines.

Design: Systematic review.

Data sources: PubMed, Scopus, and ISI Web of Knowledge.

Data Selection: Prospective field quality surveys on counterfeit and substandard medicines were selected from all available records within the selected databases up to December 31, 2013. All prospective studies performing chemical analysis on medicine samples were identified using the key search terms "counterfeit" or "substandard" and "medicine" or "drug" or "pharmaceutical." The title, abstract, and/or full articles were reviewed for relevance according to a predetermined set of inclusion and exclusion criteria. Medicines procured from the Internet are beyond the scope of this review.

Results: Sixty-six research articles were found that fulfilled our inclusion criteria. The majority of medicine quality surveys were conducted in specific areas of Africa and Asia. Within these two continents, medicine quality reports covering the Northern part of Africa and the Western part of Asia in the Middle East are extremely scarce. Other continents such as North or South America and Europe were covered in limited articles, whereas the Australian continent had no reports. Moreover, most studies examined medicines that treat infectious diseases; very few articles addressed popular medicines for chronic diseases or clinically significant narrow therapeutic index medicines or cancer treatments, despite media reports of quality problems in these medicines. Furthermore, only six (9\%) research articles attempted all levels of medicine quality analysis available through laboratory analysis, authentication of source, and package inspection to comprehensively identify the nature of the problem and so conclude whether the medicines were counterfeit or substandard.

Conclusion: Substandard and counterfeit medicines should be considered and identified through means of chemical analysis, physical analysis, authentication of source, and package inspection in any field medicine quality survey. More research is encouraged to examine the medicine quality in neglected parts of the globe and on neglected, yet popular and clinically significant, noncommunicable disease medicines.

Keywords: counterfeit, substandard, poor quality, SSFFC, medicine and drug

\section{Introduction}

Medicine safety, efficacy, and quality are the most important criteria in ensuring optimal treatment from medicines and are currently receiving increased attention in an era of 
globalization and generic manufacturing. ${ }^{1,2}$ Medicines with questionable quality could either be counterfeit or substandard, according to the World Health Organization (WHO). A counterfeit medicine is defined by the WHO as "one which is deliberately and fraudulently mislabeled with respect to identity and/or source." Counterfeiting could include both branded and generic products and may include products with the correct ingredients or with the wrong ingredients, without active ingredients, with insufficient active ingredient, or with fake packaging. ${ }^{3}$ Substandard medicines, also referred to as out-of-specification products, are defined by the WHO as "products that do not meet the required specification in terms of content and ingredients." ${ }^{\prime 4,5}$ They are legally manufactured but do not conform to specifications as a result of inadequate manufacturing or poor storage conditions. ${ }^{6-9}$ Recently, the term substandard/spurious/falsely labeled/falsified/counterfeit medicines (SSFFC) was used by the WHO to simultaneously describe both counterfeit and substandard medicines. ${ }^{10}$ This joint definition highlights the importance of identifying both counterfeit and substandard medicines in any proposed medicine quality survey.

The distinction between counterfeit and substandard medicines is imperative when applying appropriate strategies to combat potential threats of either quality problem. ${ }^{11,12}$ However, some dismiss this notion and argue that both counterfeit and substandard medicines are similar because they both claim to be something that in reality they are not. ${ }^{13}$ Nevertheless, correctly identifying the type of medicine quality problem could aid governments and responsible bodies in determining the need to involve local or international law enforcement, particularly when scarce economic resources are present. Counterfeit medicines are strongly linked with organized crime and would most likely require criminal experts to aid health care professionals to combat this problem, as demonstrated by the establishment of the International Medical Products Anti-Counterfeiting Taskforce to support the WHO efforts to combat counterfeit medicines globally. ${ }^{14}$

Medicine quality problems could be fatal in extreme clinical outcomes and have also been associated with severe economic consequences. More than 700,000 deaths from tuberculosis and malaria have been strongly linked with ineffective counterfeit and substandard medicines worldwide..$^{15,16}$ Mortality has also been reported after heparin contamination in the United States and sexual enhancement drugs adulterated with large contents of hypoglycemic drugs in Singapore. ${ }^{17-20}$ Moreover, substandard and counterfeit medicines have been related to morbidity, drug resistance, therapeutic failure, and toxicity. ${ }^{8,13,15,16}$ Economically, substandard and counterfeit medicines have been suggested to cause macroeconomic burdens worldwide by wasting limited resources, causing loss of productivity, and limiting investment of major pharmaceutical companies into medicine research and development. ${ }^{7,8,21}$ Furthermore, consequences of substandard and counterfeit medicines could result in loss of confidence in health care professionals and/or services. ${ }^{8,13,15,16}$

The WHO estimates that around $10 \%$ of all global pharmaceutical supply is counterfeit and substandard, reaching up to $50 \%$ of the supply in developing countries and as low as $1 \%$ in the developed world. ${ }^{6,15,22}$ Moreover, it has been suggested that the majority of reported SSFFC medicines were substandard, rather than counterfeit, yet they receive far less attention within the media and the scientific community. ${ }^{23,24}$ Determining the exact prevalence rates of either counterfeit or substandard medicines could be a complex task and requires high-quality country-based medicine surveys, which are limited within the available literature.

The aim of this systematic review is to broadly explore the evidence of substandard and counterfeit medicines in scientific reports to identify current knowledge limitations and provide an overview report of the current situation. Previously, some reviews have focused on specific medicine categories or problems. ${ }^{13,23,25,26}$ Only one review comprehensively searched for substandard and counterfeit medicine articles covering the period from 1966 to 2006 without specifying a therapeutic medicine category. ${ }^{27}$ Recently, the first systematic review on the subject of counterfeit and substandard medicines was published. ${ }^{28}$ However, Almuzaini et al have only reviewed some articles from a single therapeutic class that demonstrated highquality reporting, which could be useful in the determination of SSFFC prevalence rates but may not be comprehensive enough to describe the broad scope and nature of SSFFC medicines available in other reports. Further, the previous systematic review did not discuss the types of analysis performed in the included studies, nor did it identify therapeutic classes or global regions in which the quality of medicines remains largely unknown. This review attempts to cover these issues broadly to encourage future researchers on medicine quality to focus their attention on neglected medicines and neglected parts of the globe. Furthermore, this review discusses types of analysis currently performed in medicine quality surveys to identify areas of concern and to promote the consideration of counterfeit as well as substandard medicines when conducting any medicine quality survey. 


\section{Methods}

\section{Searching the literature}

Scopus, PubMed, and ISI Web of Knowledge databases have been searched for relevant research articles. The search covered the period from 1997, the year the first relevant citation was found, up to December 31, 2013. There was no language restriction applied on our search results.

The following key search terms were used in conjunction, using (AND) to identify related articles: substandard(s) or counterfeit(s); medicine(s) or drug(s) or pharmaceutical(s). The choice of key search terms was based on key search terms used in five previous literature reviews. ${ }^{13,23,25-27}$ The main distinction of our present review compared with most previously published reviews is its systematic nature and broader scope, as no medicine groups or settings were specifically chosen in the search terms and inclusion criteria used.

The definitions and criteria used to describe counterfeit and substandard medicines in this review are based on the widely accepted WHO definitions of each phenomenon, as cited earlier. ${ }^{3-5}$ On the basis of the WHO criteria, a counterfeit medicine could be determined by chemical analysis methods if medicine samples contained no, or the wrong, active ingredient. A counterfeit medicine could also be identified via medicine package analysis by visual comparison to a known genuine package. Other means of detecting counterfeit medicines include authenticating its source through official consignment documents or communication with the stated manufacturer and regulatory organizations. In addition, deliberately manufactured substandard medicines are considered counterfeit, although this would be difficult to demonstrate without legal and criminal investigation by authorities. In contrast, a substandard medicine should always contain the correct active pharmaceutical ingredient (API), be produced from a legitimate source, and be without packaging defaults. Substandard medicines are present when the amount of API is outside the acceptable pharmacopeial limits, the sample does not meet other standards set by the pharmacopoeias, or medicines are past their expiry dates. Collectively, we refer to both counterfeit and substandard medicines as SSFFC medicines, in accordance with the latest WHO joint definition. ${ }^{10}$

\section{Inclusion and exclusion criteria for articles in this review}

Studies included in this review were original research articles that reported prospective medicine sample collection from their natural settings; these medicines were presumed to be readily available to patients. Further, all included articles must have reported conducting chemical tests for the identification and/or quantification of the API. Without performing chemical analysis, it would not be possible to determine whether a medicine sample was counterfeit or not, as no information on the API would be present. In addition, relevant studies would include medicine samples from a wide range of different therapeutic categories and dosage forms without any restrictions.

In contrast, the exclusion criteria of articles would include studies that did not report primary collection of medicine samples or medicines procured from the Internet or retrospectively collected through authority or innovator company seizures. Furthermore, studies that reported only physical or packaging testing without chemical analysis were excluded. Duplicate results and nonrelevant articles were also identified and excluded from this review.

\section{Data presentation of articles in this review}

This systematic review has been performed in accordance with Preferred Reporting Items for Systematic Reviews and Meta-Analyses guidelines for systematic reviews. ${ }^{29}$ All percentages of SSFFC medicines available in this review are reported as cited from their primary source. Therefore, caution is advised, as methodological differences exist between articles. The data presented here do not allow for any estimation of the SSFFC prevalence rate worldwide.

\section{Results Data extraction}

The use of the selected search terms resulted in a total of 3,861 hits from all databases. An initial screening of titles/ abstracts followed this, excluding nonrelevant and duplicate results to reduce the number of results to 1,288 research articles. Subsequently, a full review of articles was performed that further excluded articles without primary data collection, such as reviews and opinions, articles containing retrospective sample collection of medicines (either donated or seized by authorities), medicines acquired through the Internet, nonrelated articles, studies without medicine sample collection, and studies that did not perform chemical analysis of samples. This strategy reduced the final number of the included articles to 66. A flowchart illustrating the method used for article selection in this review and different exclusion categories is shown in Figure 1. 


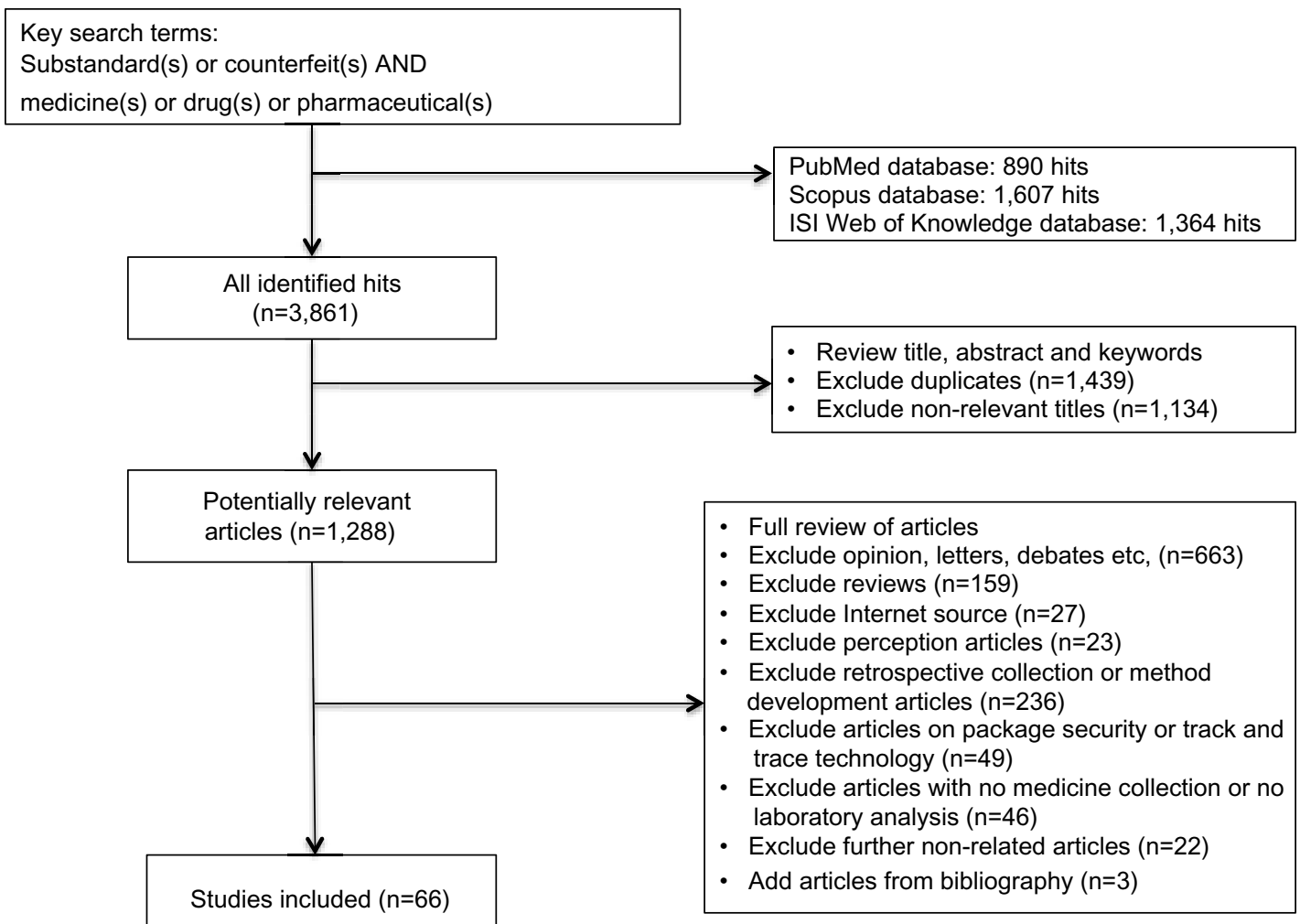

Figure I Flow chart for articles inclusion in systematic review.

\section{Location of included studies}

The majority of reported studies prospectively examining SSFFC medicines were conducted in the African continent (31/66; 47\%). Nigeria and Ghana alone were selected for more than 50\% (17/31) of the studies in Africa. In Asia, 23/66 (35\%) of the SSFFC medicine quality surveys were conducted, mostly in the South Eastern part of Asia (Tables 1-4). Eight research articles were performed in the southern parts of the continent in Pakistan, Bangladesh, and India. ${ }^{30,32,37,54,61,72,76,78}$ Overall, only two studies (3\%) were published that addressed SSFFC medicines in the western part of Asia, also known to be part of the Middle East. ${ }^{82,87}$ Elsewhere, 6/66 (9\%) of studies were conducted in more than one continent simultaneously. ${ }^{30,32,53,71,79,92}$ Moreover, three studies were performed in North/South America (4\%), ${ }^{65,67,68}$ and two in Eastern Europe $(3 \%){ }^{83,84}$ Only one study was located in the borderline area between Asia and Australia in Papua New Guinea. ${ }^{33}$

\section{Medicine therapeutic classes in included studies}

Substandard and counterfeit medicines were found from various therapeutic categories. However, most SSFFC studies 57/66 (86\%) were focused on medicines that treat infectious diseases. Antimalarial, antibiotic, and antituberculosis medicines were examined in 30/66 (46\%), 10/66 (15\%), and $5 / 66(8 \%)$ of the located studies, respectively (Tables 1, 2, and 4). The combination of more than one class of medicines to treat infectious diseases was found in 12/66 (18\%) of the articles. ${ }^{32,33,37,39,42,47,51,53,71,72,79,89}$ Other infectious diseases such as leishmaniasis medicines were investigated on one (2\%) other occasion. ${ }^{54}$ In contrast, medicines for treatment of noncommunicable diseases were present in only 9/66 (14\%) of the cited literature. ${ }^{31,32,47,58-60,67,77,80}$ The analgesic paracetamol was investigated on two separate occasions. ${ }^{32,58}$ Similarly, antihypertensive medications were surveyed in only two studies. ${ }^{59,77}$ Nonsteroidal anti-inflammatory agent aspirin was analyzed in one further study. ${ }^{47}$ The antihistamine medicine chlorpheniramine was only present in one survey. ${ }^{60}$ Narrowtherapeutic index medicines also were the focus of only one published study.$^{67}$ Other types of medicines such as ergometrine, oxytocin, and erythropoietin appeared in only one study each. ${ }^{31,80}$ A single study attempted to collect samples from various therapeutic categories simultaneously. ${ }^{32}$

\section{Evidence and nature of SSFFC medicines}

Overall, substandard medicines were found in the majority of prospective SSFFC medicine studies (60/66; 91\%) (Tables 1 and 4). Counterfeit medicines were less evident in 


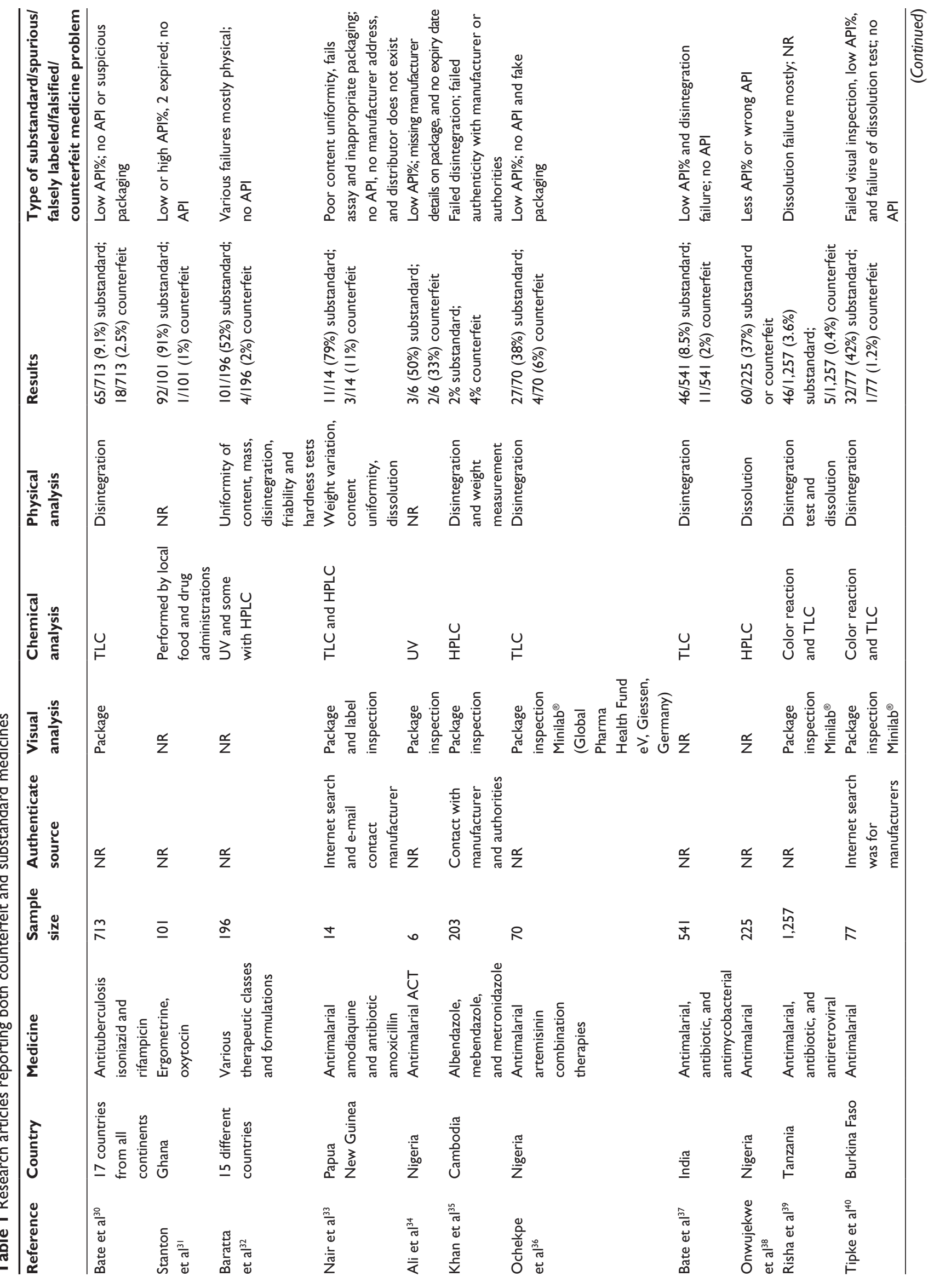




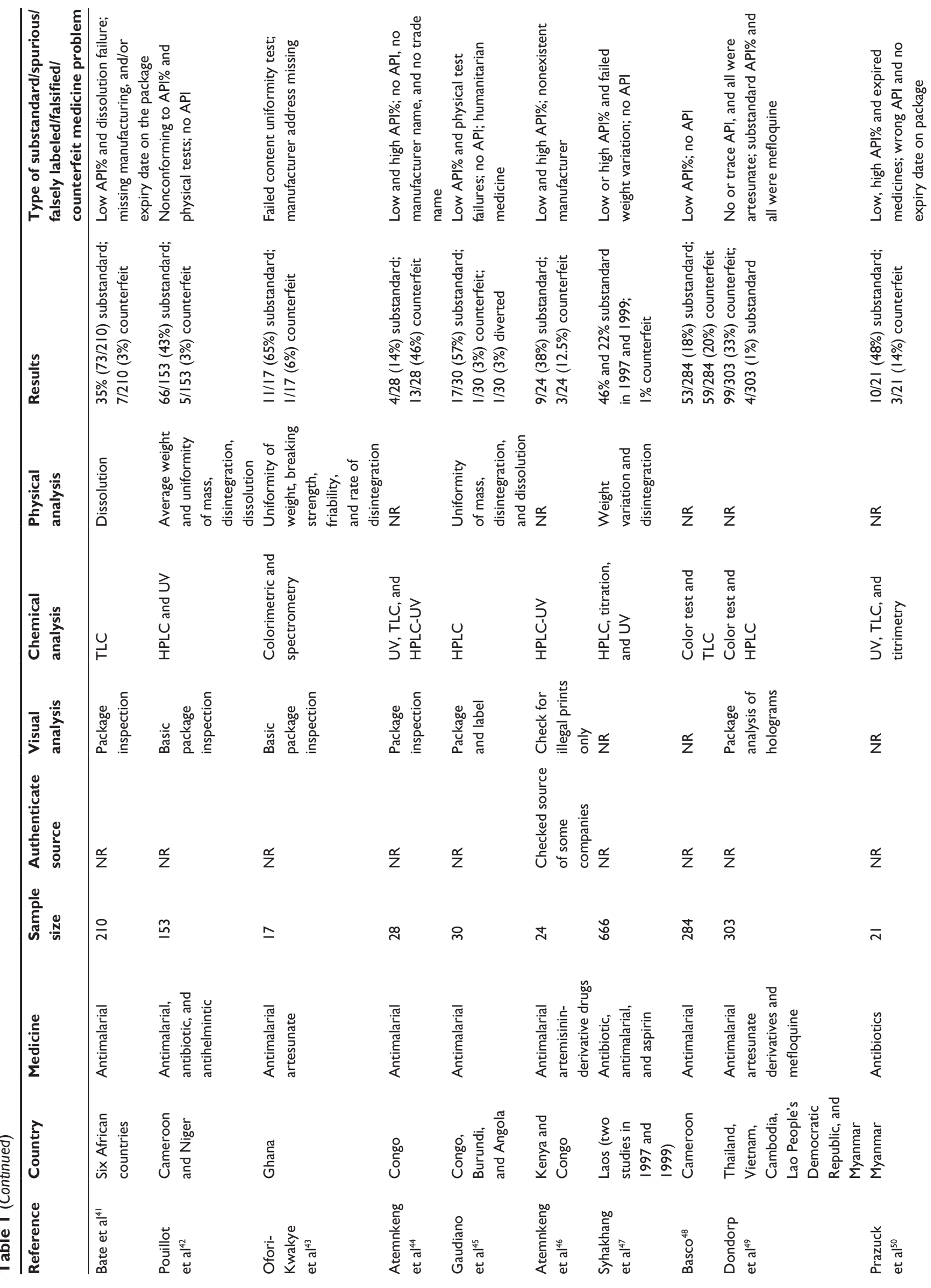




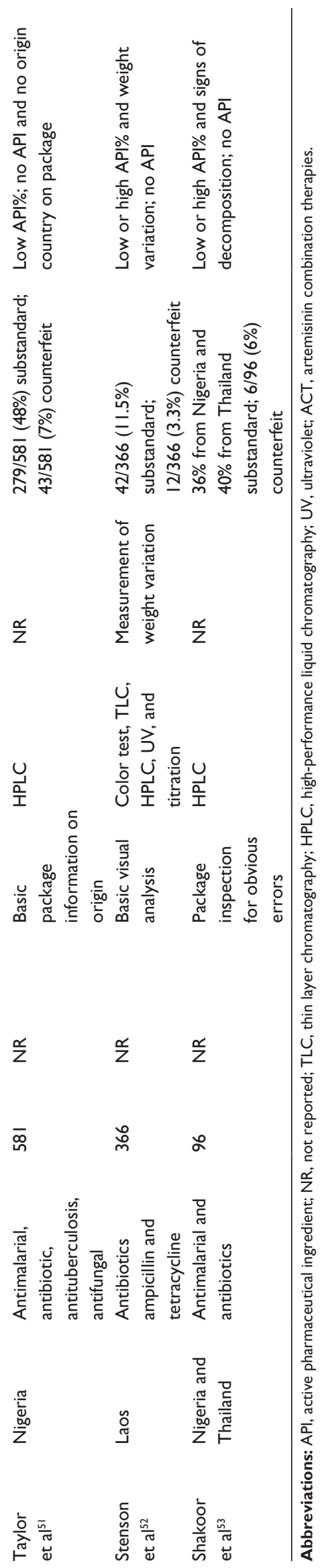

29/66 (44\%) of available studies (Tables 1 and 2). Counterfeit and substandard medicines were simultaneously found in 24/66 (36\%) articles (Table 1). Few studies 5/66 (8\%) reported only evidence of counterfeiting in the medicine samples collected (Table 2). Evidence of medicines being only substandard, rather than counterfeit, was found in $36 / 66$ (55\%) of the articles (Table 4). One study did not find evidence of counterfeit or substandard medicines in their sample (Table 3).

Several types of SSFFC problems have been reported in the selected literature. It was noted that more than one medicine quality problem typically exists within each prospective medicine quality survey (Tables 1, 2, and 4). The most reported medicine quality problem was failure to comply with the specified API limits in 46/66 (70\%) of cases (Tables 1 and 4). Failure of dissolution or disintegration tests has been reported in 24/66 (36\%) of the articles (Tables 1 and 4). The presence of either no API ${ }^{12,31-33,36,37,40,42,44,45,47-49,51-56}$ or the wrong API ${ }^{12,38,50,55}$ was reported in 20/66 (30\%) and 4/66 (6\%) cases, respectively. Other problems were also reported, including fake package, ${ }^{36,57}$ fake hologram, ${ }^{12,56,57}$ manufacturer does not exist, ${ }^{12,33,46}$ manufacturer confirmed a nonauthentic batch, ${ }^{35,56}$ expired medicines, ${ }^{31,50,68}$ no origin country stated, ${ }^{51}$ no manufacturer address, ${ }^{33,34,43}$ no manufacturer stated, ${ }^{44}$ no expiry date, ${ }^{34,41,50}$ unusual interval between manufacturing and expiry date, ${ }^{55}$ wrong name on package or leaflet, ${ }^{12}$ wrong spelling of "tablet,", 55,56 use of a different font ${ }^{56}$ different medicinal taste, ${ }^{57}$ heavier weight, ${ }^{57}$ nonauthorized manufacturer ${ }^{86}$ absence of trade name, ${ }^{44}$ signs of deterioration, ${ }^{53}$ and diverted medicines ${ }^{45,80}$ intended for distribution in one location and found to be on sale in another market.

\section{Type of analysis identified in the included studies}

Four distinctive types of analysis can be used to distinguish between a genuine and SSFFC medicines; namely, authentication of the supplier, visual package inspection, and chemical and physical analysis (Tables 1-4). Authentication of the medicine source via contact with manufacturer, health regulatory agencies, or Internet search has been only attempted in 10/66 (15\%) of the selected studies. $12,33,35,40,46,56,62,80,86,88$ Package inspection was more popular than authentication, being reported in 39/66 (59\%) of studies, with the majority reporting obvious spelling errors and basic label information (medicine name, dosage, manufacturer, expiry date, and lot number), as shown in Tables 1,2, and 4. As for the chemical analysis, high-performance liquid chromatography and thinlayer chromatography (TLC) were most widely used in 40/66 


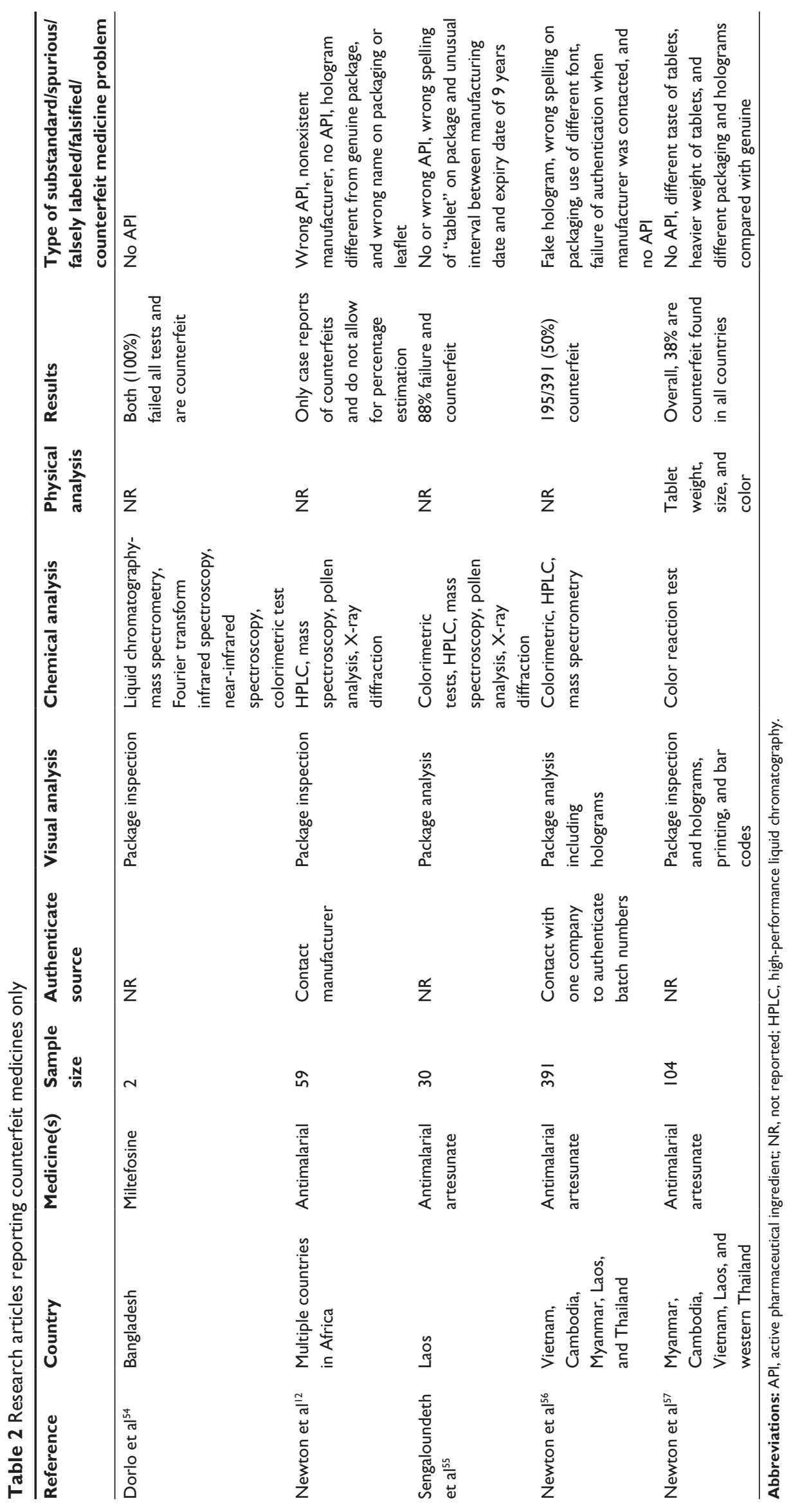


Table 3 Study with no report of substandard or counterfeit medicines

\begin{tabular}{lllllllll}
\hline Reference & Country & Medicine & $\begin{array}{l}\text { Sample } \\
\text { size }\end{array}$ & $\begin{array}{l}\text { Authenticate } \\
\text { source }\end{array}$ & $\begin{array}{l}\text { Visual } \\
\text { analysis }\end{array}$ & $\begin{array}{l}\text { Chemical } \\
\text { analysis }\end{array}$ & $\begin{array}{l}\text { Physical } \\
\text { analysis }\end{array}$ & Results \\
\hline Said et al ${ }^{58}$ & Malaysia & Paracetamol & 16 & NR & NR & $\begin{array}{l}\text { Near-infrared } \\
\text { spectroscopy }\end{array}$ & NR & $\begin{array}{l}\text { All samples passed but } \\
\text { with variable quality }\end{array}$ \\
\hline
\end{tabular}

Abbreviation: NR, not reported.

(61\%) and 19/66 (29\%) of studies, respectively (Tables 1 , 2 , and 4). Other chemical analysis methods were reported such as color reaction tests, ${ }^{39,40,43,48,49,52,54-57,66}$ spectroscopic techniques, ${ }^{12,43,54-56,58,61,63,69,71,72,75,79,92}$ and titration, ${ }^{47,50,52,59,63,73}$ but remain less frequently used. Moreover, physical analysis tests were performed in 39/66 (59\%) of the studies (Tables 1, 2 and 4). The most common physical tests reported were disintegration and/or dissolution tests in 36/39 (92\%) cases (Tables 1, 2, and 4). Other less frequently used physical analysis tests include content uniformity, ${ }^{33,42,43,45,66}$ weight measurement, ${ }^{33,35,42,47,52,57,60,63,65,67,73}$ hardness, ${ }^{32,65,73}$ and friability $^{32,43,60,65,73}$ tests. Interestingly, only six studies (9\%) reported all four types of analysis in an attempt to clearly identify and classify the type of SSFFC problem, where present, in any medicine sample. . $^{33,35,40,62,86,88}$

\section{Discussion}

\section{Neglected parts of the world in SSFFC surveys}

According to our findings, the vast majority of prospective medicine quality studies were conducted in small parts of Africa and Asia. These efforts can be attributed to an attempt to counteract nonexistent or lower levels of regulation in these pharmaceutical markets. ${ }^{94}$ However, some parts of these two continents still have limited scientific research addressing the problem of SSFFC medicines, mainly in the Middle East and North Africa. In Yemen, 32\% of selected antimalarial medicines failed analysis tests, and the majority of these were substandard, having lower than accepted API\% limits and unacceptable dissolution rates. ${ }^{87}$ Another study explored the API content of the antibiotic amoxicillin purchased from Egypt, Lebanon, Jordan, and Saudi Arabia and found that more than $50 \%$ of samples had lower API\% than accepted by pharmacopeial limits, and therefore were considered substandard. ${ }^{82}$ A multicountry medicine quality survey found that $12 \%$ of samples collected from Egypt failed at least one medicine quality test and can be considered substandard. ${ }^{71}$ None of these studies reported an attempt to verify the source or analyze packages of the selected medicine samples to explore the possibility of counterfeiting activity. This may cause some concern, particularly with recent seizures of SSFFC medicines in this area. In addition, the currently unsettled political situation may be a catalyst for the increased prevalence of SSFFC medicines, as it allows them to escape immediate governmental attention..$^{95}$ Reports of recent seizures of SSFFC medicines in this area can be mostly found in the media, which remains the main source of information regarding SSFFC medicines in this region with limited published scientific reports. ${ }^{95}$ Moreover, a WHO report on questionnaire responses from a number of health organizations in the Eastern Mediterranean Regional Office regarding counterfeit medicines has confirmed counterfeit seizures in this region by some respondent countries. ${ }^{96}$ In addition, this area could be of specific importance in terms of geographical location, as it separates two well-established regions of SSFFC medicine prevalence, according to our data, and is en route between potential counterfeit manufacturers in $\mathrm{Asia}^{56}$ and their global targeted markets. It is therefore suggested that several pilot studies be conducted to survey the quality of medicines in the Middle East and North Africa to assess the current medicine quality situation before any countermeasures or large-scale medicine quality surveys can be recommended. Elsewhere, such pilot studies have been shown to be instrumental in the assessment of the medicine quality situation in different countries and to have justified the need for further medicine quality surveys, where appropriate. ${ }^{30,37,57,78}$

Evidence from South America suggests that SSFFC medicines are available, but with only limited scientific research. A study found $11 \%$ of antimalarials to be substandard in seven South American countries using basic TLC chemical analysis. ${ }^{68}$ The TLC analysis technique is limited by its inability to detect higher than $80 \%$ of API concentration in medicine samples ${ }^{41}$ which has been evident to exist in previous studies. ${ }^{31,41,44,46,50,52,53,61,63,66,70,73,76-78,87,91,93}$ It is therefore possible that the prevalence of SSFFC medicines in South America could be higher than the reported figures if more sophisticated chemical techniques for the quantification of API $\%$ content were used, such as high-performance liquid chromatography. Another study reported problems with low API\% on a range of medicines procured from Mexico; of particular importance are some narrow therapeutic index 


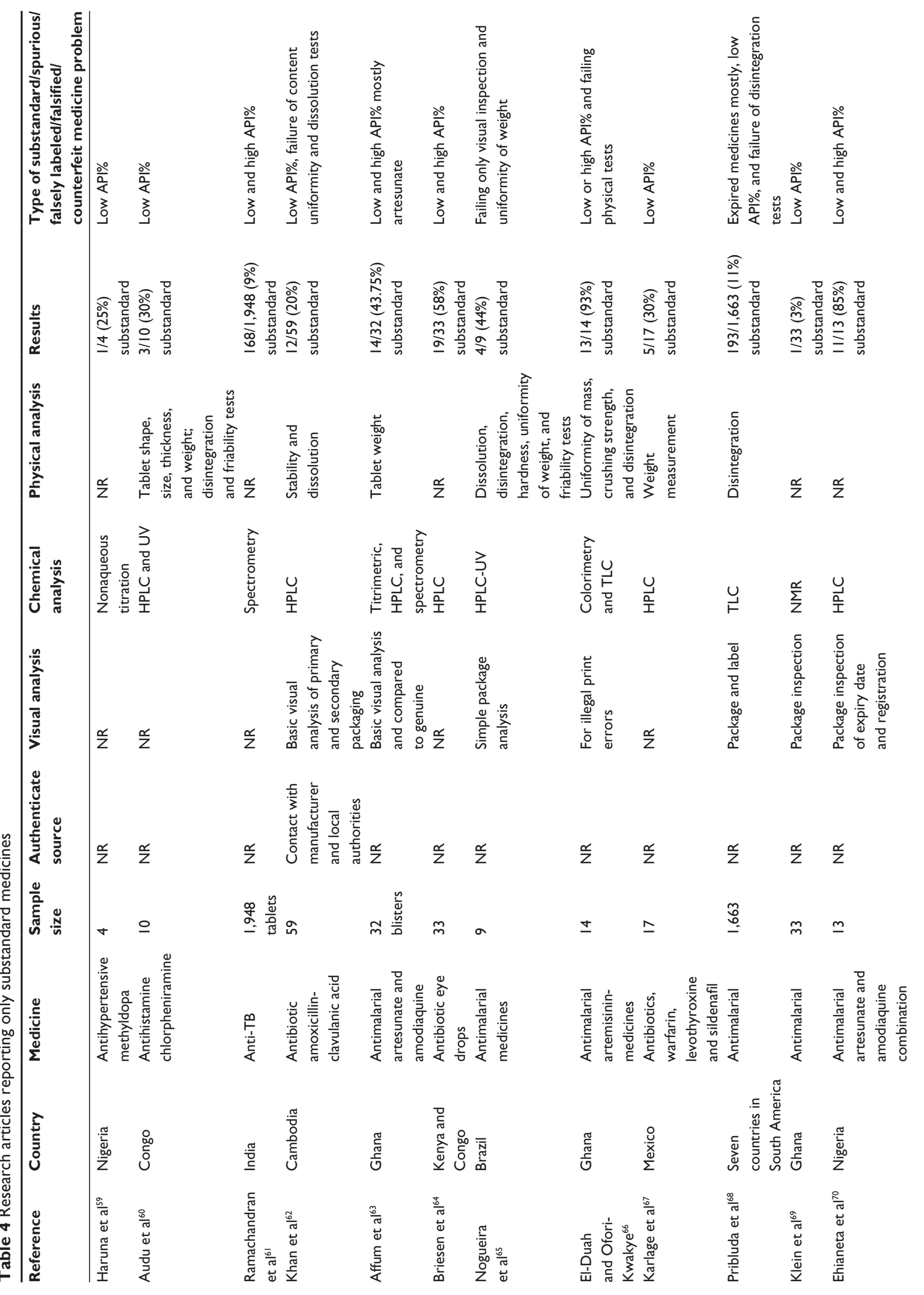



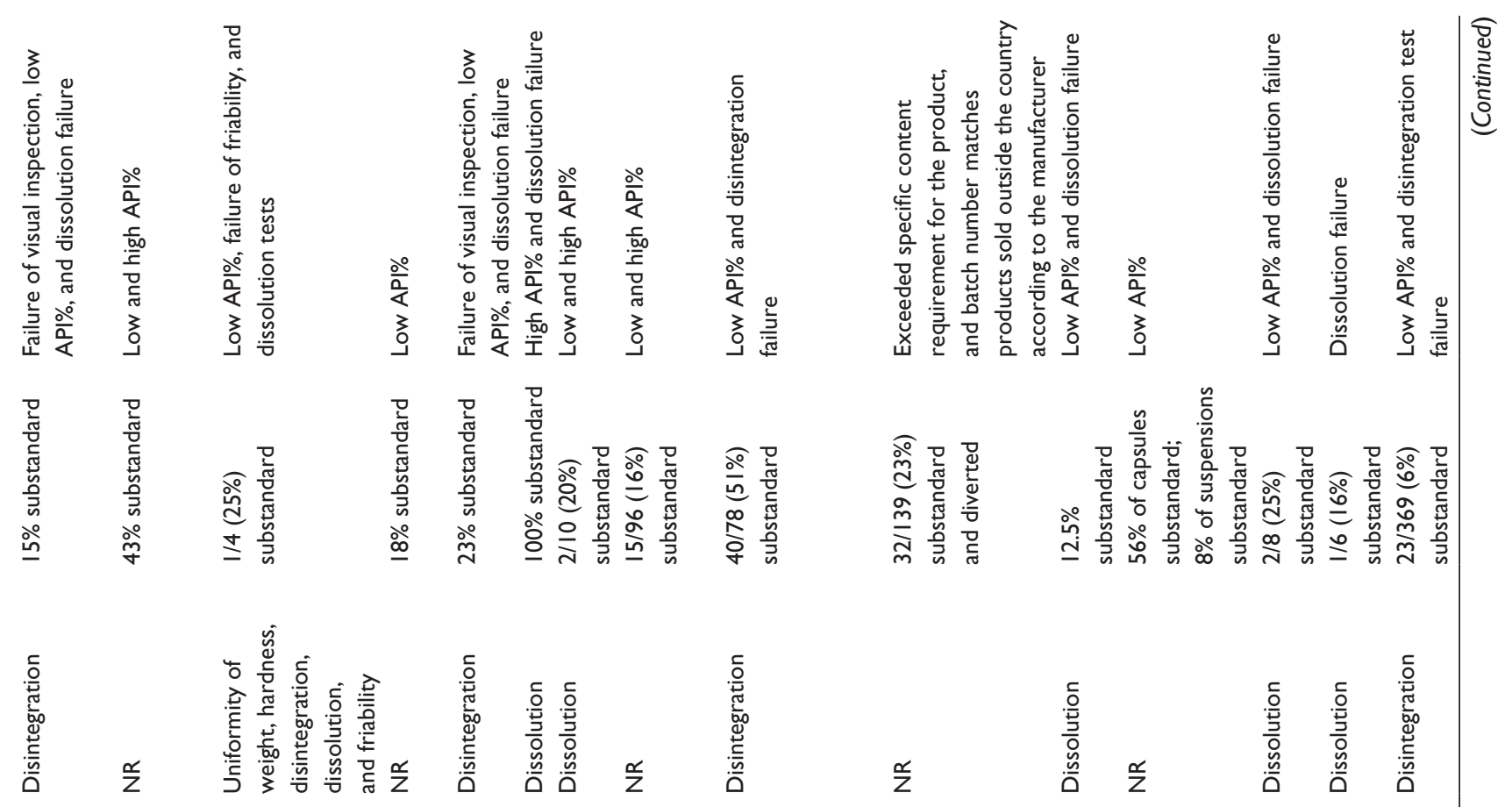

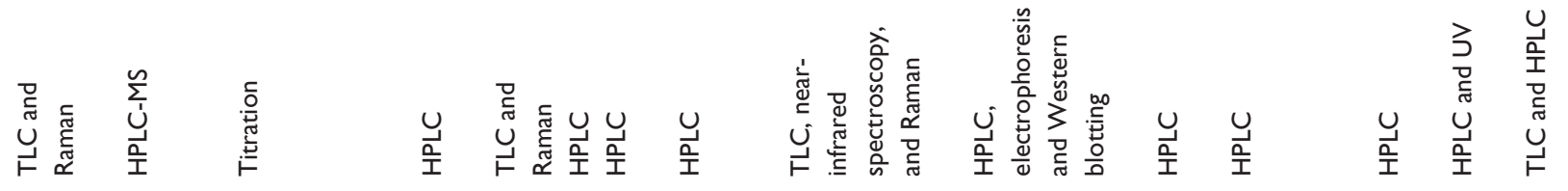

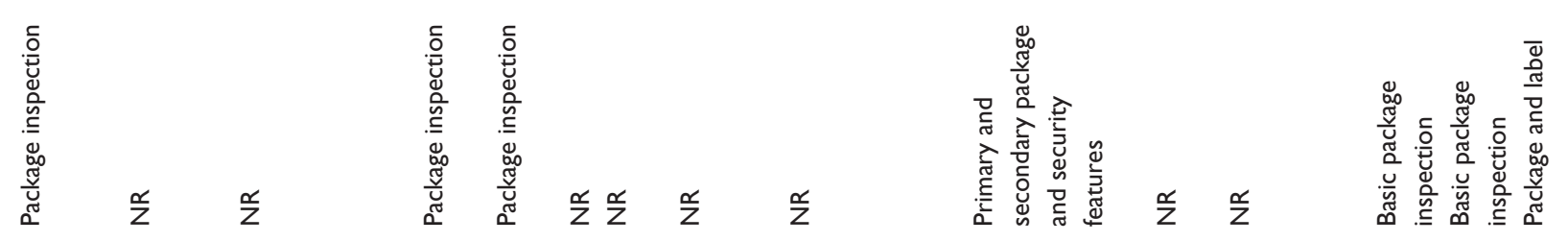

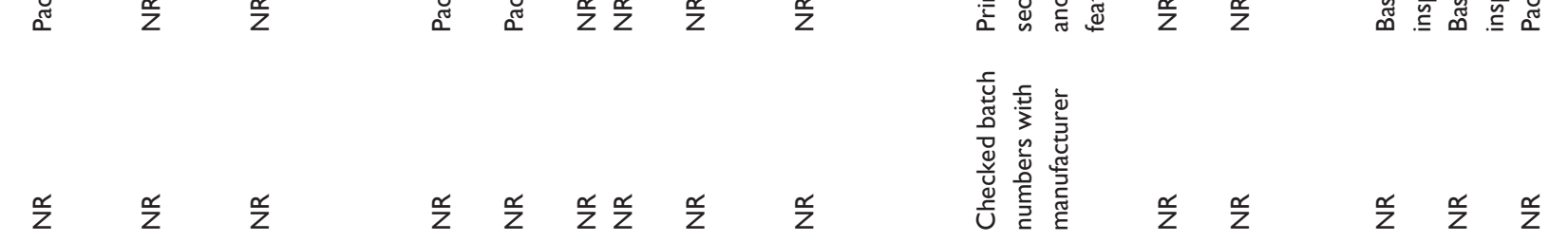

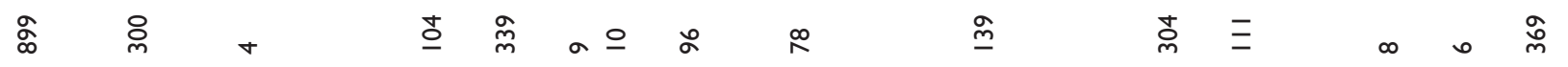

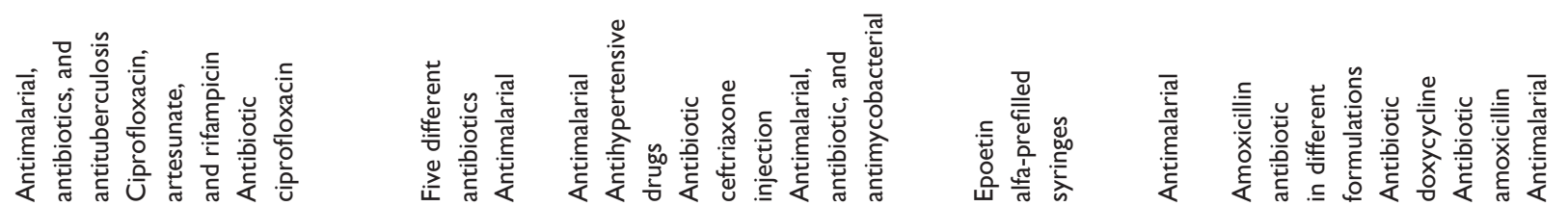

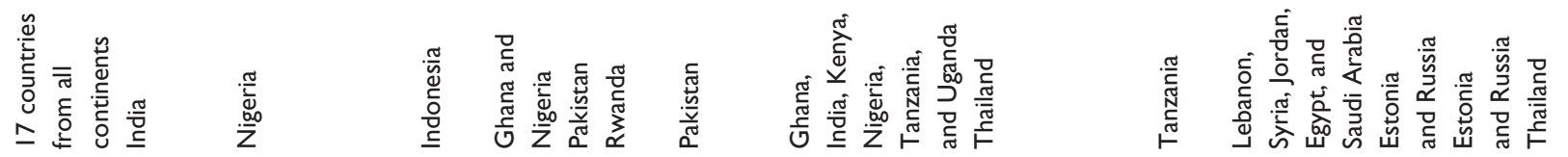

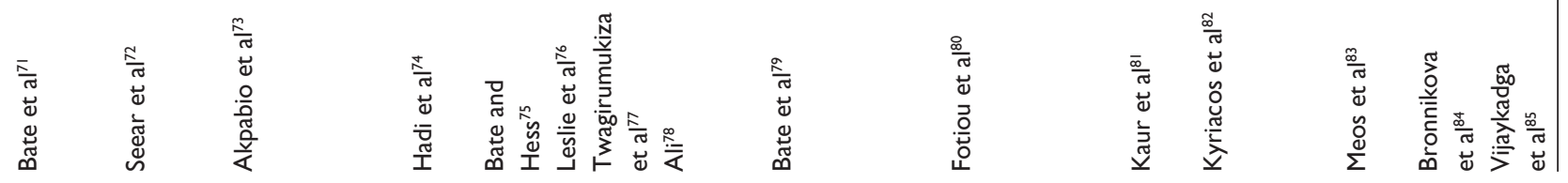




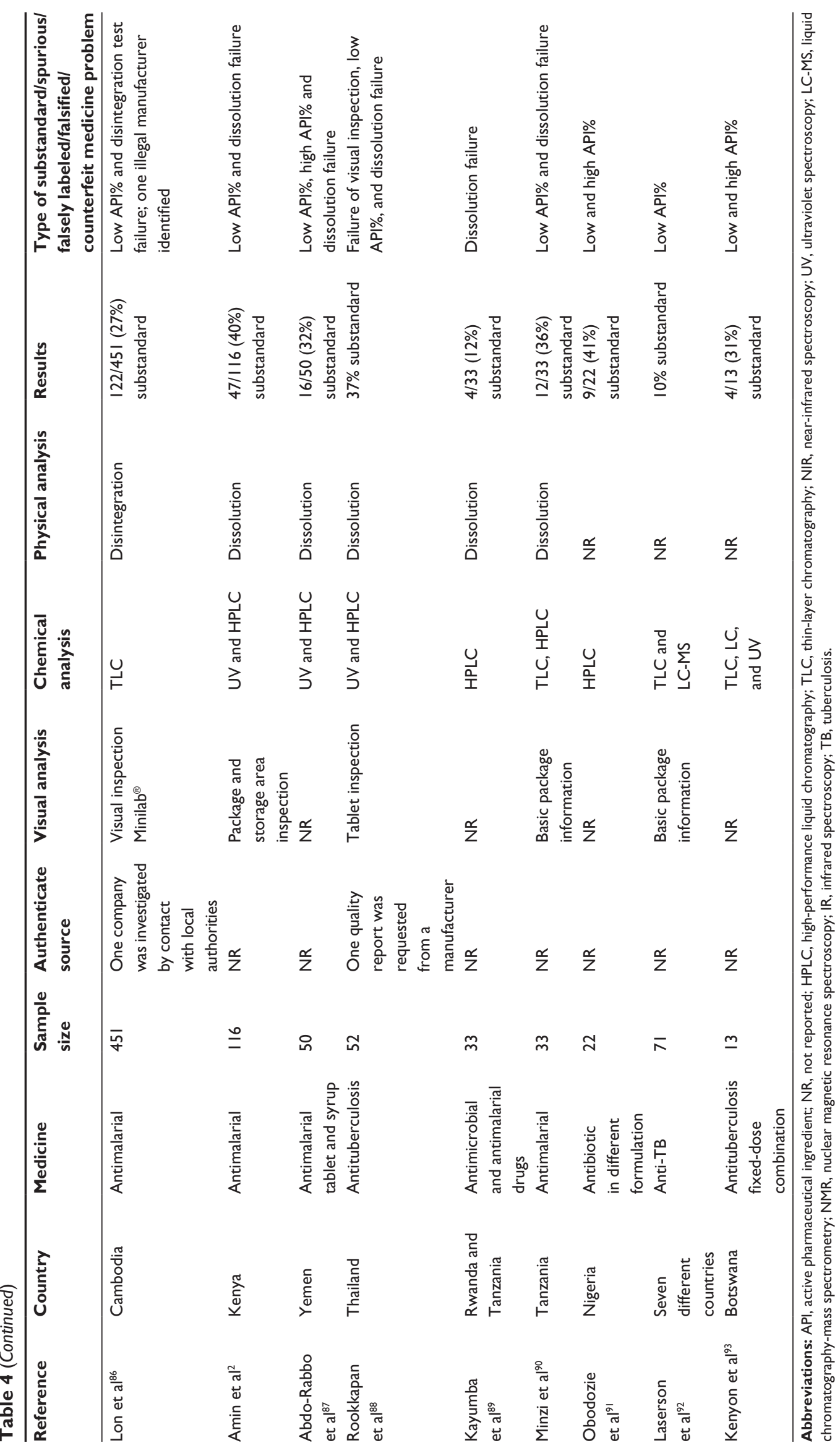


medicines such as warfarin and levothyroxine. ${ }^{67}$ Two studies from Eastern Europe found some problems regarding low API\% and dissolution failures when a limited number of antibiotics were analyzed in Estonia and Russia. ${ }^{83,84}$ No studies could be identified that addressed medicine quality problems in the Australian continent.

\section{Neglected noncommunicable medicines in SSFFC surveys}

Most of the studies in this review were found to explore medicines used to treat infectious diseases such as malaria and tuberculosis. Medicines used to treat noninfectious diseases, also known as noncommunicable disease (NCD) medicines or chronic disease medicines, were only found in a few studies that presented some medicine quality problems. ${ }^{31,32,47,58-60,67,77,80}$ However, on a global scale, NCDs and their medicines must not be ignored. The WHO estimates that NCDs kill more than 36 million people each year, of which 29 million deaths $(80 \%)$ occur in low- and middle-income countries. ${ }^{97}$ The currently available literature on medicine quality does not reflect the wider use of NCDs and their medicines globally, including in lower-income countries. This issue needs to be addressed rapidly, as recent evidence from Pakistan reported the death of more than 100 people after the administration of the antianginal medicine isosorbide mononitrate contaminated with large amounts of pyrimethamine. ${ }^{98,99}$ Elsewhere, the US Food and Drug Administration recently issued warnings regarding counterfeit cancer medicines. ${ }^{100,101}$ Furthermore, evidence of counterfeiting involving NCD medicines such as diabetes treatments were found in illicit or lifestyle drugs, which may have significant implications for the public health and could result in death. ${ }^{17,102,103}$ Therefore, it is recommended that we extend the attention of future medicine quality surveys globally beyond infectious diseases medicines and on to NCD medicines (and widely available treatments of diabetes and cardiovascular diseases in particular), in addition to cancer treatments and narrow therapeutics index medicines, as they could have severe health implications for the affected population.

\section{Type of analysis used in SSFFC surveys}

All studies included in this review performed chemical analysis for the identification and/or quantification of the API available in selected samples, in accordance with our methodological approach. High-performance liquid chromatography and TLC were the most widely used chemical analytical techniques available in the selected articles, possibly because of their wide acceptance in the academic field and their application in many pharmacopeial references. It is suggested that this would be a logical and possibly important consideration for future scholars interested in conducting medicine quality surveys to ensure the acceptance of their findings within the academic field.

Physical analysis tests were performed to complement chemical analysis in approximately two-thirds of the selected studies, particularly disintegration and dissolution tests for solid dosage forms. This can be attributed to the availability of specific physical tests in different pharmacopoeias in addition to the use of physical information about the medicinal product to predict the bioavailability of medicines. ${ }^{2,45,88}$ However, such physical analysis tests could only be used as a bioavailability indicator and cannot substitute lengthy and expensive bioavailability studies. ${ }^{89,93}$ Moreover, it is important to note that performing physical analysis only on medicinal samples can be considered inadequate if the objective of the study was to determine medicine quality issues, as it cannot be determined whether the correct API and its quantity are present in medicine samples, as specified in the WHO definition of substandard and counterfeit medicines. ${ }^{3-5}$

Package inspection is another popular type of medicine analysis that was also found in nearly two-thirds of the medicine quality surveys in this review. On the basis of primary and secondary package information, the majority of reports seek obvious spelling errors, suspicious holograms compared with known genuine samples, and basic label misinformation such as medicine name, dosage, manufacturer details, expiry date, and lot number (Tables 1, 2, and 4). The WHO definition of counterfeit medicines highlights packaging information significance and could have influenced the wide use of package information among medicine quality surveys. ${ }^{3}$ Furthermore, packaging information of medicines has been a valuable mode of analysis in the relevant literature and has revealed many counterfeit medicines that have passed chemical identification tests. ${ }^{34,41,43}$ A tool kit developed by the World Health Professions Alliance and the International Pharmaceutical Federation for visual inspection of medicines can be used for a systematic package inspection by health care professionals and scholars both in practice and in future investigative projects. ${ }^{104}$

A less common level of analysis available in the literature is the authentication of medicine source via contact with the medicine manufacturer and local or international health authorities. We have identified only ten research articles that attempted to authenticate the source of the medicine samples. ${ }^{12,33,35,40,46,56,62,80,86,88}$ Perhaps researchers 
may not guarantee adequate responses to their queries from other parties, as some have suggested. ${ }^{33,35}$ It could also be possible that authenticating the source may not be within the scope of a particular medicine quality survey, as it could be only focused on substandard medicines issue. ${ }^{51}$ Nevertheless, the WHO definition of counterfeit medicines clearly describes the deliberate and fraudulent misrepresentation of the medicine source as a characteristic of a counterfeit medicine. ${ }^{3}$ Moreover, according to the Pharmaceutical Security Institute, counterfeit medicines are currently increasing in terms of reported incidences worldwide and can no longer be ignored. ${ }^{105}$ We recognize that obtaining authentication confirmation of medicine sources could be difficult in studies collecting samples from street markets; however, this task could be less complex when samples are collected from pharmacies or hospitals, as official records and documentation of medicines are expected to exist. Furthermore, according to the limited studies that reported authentication analysis in this review, many counterfeit cases were found by confirmation from manufacturers or health authorities of a nonauthentic batch of medicines, even if samples contained the correct API when chemically analyzed. ${ }^{35,46,86}$

Overall, there were very few research articles that performed all four levels of analysis: chemical, physical, package inspection, and authentication of source..$^{33,35,40,62,86,88}$ Future medicine quality surveys are advised to consider performing all four types of analysis for a more holistic approach, and equally, to address the possibility of finding either counterfeit or substandard medicines during an investigation. Further, it was noted that none of the medicine quality surveys examined patient information leaflets within medicinal packages to check for accuracy and up-to-date information made available to patients. Some studies, particularly in the Middle East, have found disagreement between patient information leaflets in some medicine samples when compared with national formularies. ${ }^{106,107}$ Therefore, the addition of patient information leaflets to examination of medicine samples in medicine quality survey studies is open for debate among the scientific community.

\section{Prevalence of SSFFC}

Our data suggest that reports of substandard medicines are more widely available in the literature, particularly medicines with incorrect API $\%$ and failure of dissolution/disintegration tests, than counterfeit medicine reports (Tables 1-4). These findings are in line with previous reports that suggested that substandard medicines are more prevalent than counterfeits and require more global attention..$^{23,24}$ This phenomenon might be attributed to poor manufacturing practices or extreme weather conditions in some countries, accompanied by inadequate storage conditions. ${ }^{4,5,82}$ However, because the majority of cited articles in this review did not conduct authentication processes via contact with manufacturers and/or health authorities, as previously mentioned, medicine counterfeiting remains a possibility that has not been largely explored. Hence, considering the available data, it cannot be determined whether substandard medicines are indeed more prevalent than counterfeit medicines at this time. Future medicine quality researchers are therefore encouraged to remain vigilant about counterfeiting possibility and conduct all types of analysis including chemical, physical, package inspection, and authentication efforts to determine the type of medicine quality problem more accurately.

\section{Limitations of this review}

This systematic review is not without limitations. Articles conducting chemical analysis were a prerequisite for inclusion in this review. We focused only on prospective field quality surveys and excluded reporting of any studies with retrospective or previously seized SSFFC medicines in the literature. Studies proposing novel chemical or physical analytical techniques and methods are typically conducted on previously seized samples of SSFFC medicines, and therefore would not be covered within this review. Our search strategy has limited our findings to the search terms used and the databases searched. We did not search for articles on the Internet in an attempt to preserve the systematic nature of our study. The Internet source of medicines was beyond the scope of our review. Relevant articles from the bibliographical list of available studies were only included on some occasions and cannot be considered exhaustive. The included articles were not assessed for the quality of their methodology, which was found to vary considerably among the selected articles. The primary author was the only individual who performed the identification, selection, and inclusion of articles in this review. No attempt was made to calculate prevalence rates of SSFFC medicines or test for statistical significance, as it would have resulted in the exclusion of most articles from this review, as most reported studies used convenience sampling and/or with limited sample size. ${ }^{11}$

\section{Strengths of this review}

This review has several strengths. To our knowledge, it is only the second systematic review on the subject of 
SSFFC medicines. Evidence of SSFFC medicines in terms of nature and type of analysis were discussed. This information would most likely aid government agencies and health care authorities and scientists interested in the medicine quality issues in developing or improving current policies and practices. It was the intention of this review to help interested parties identify and describe SSFFC medicine problems with up-to-date scientific evidence. Further, this review highlighted neglected medicine types and neglected geographical location in terms of scientific research addressing SSFFC medicines. This could invite more research projects addressing these neglected medicines and geographical locations to improve current knowledge on the issue and maintain patient safety. Moreover, this review has identified the limited scientific research, conducting field quality surveys on SSFFC medicines, using all four levels of analysis, in an attempt to encourage future researchers to explore all possibilities when conducting a medicine quality survey in any settings.

\section{Conclusion}

The problem of SSFFC medicines is evident worldwide. Potential harm to patients' health requires global collaboration exceeding the status quo. Limited research addressing SSFFCC medicines was noted in several parts of the world, including the Middle East, North Africa, and Australia. Similarly, more research is required to address SSFFC medicines from noncommunicable medicine classes, including narrow therapeutic index and chronic medicines, as current scientific knowledge regarding these medicines remains limited despite their popularity and media reports of the existence of SSFFC medicine problems in such therapeutic classes. Furthermore, the current focus of published research on chemical and physical analysis of medicine samples could overlook the possibility of counterfeiting if additional steps of analysis were performed, including package inspection and authentication of source via contact with manufacturers and health authorities. Future medicine quality surveys are encouraged to perform all four levels of analysis to explore all possibilities of substandard and counterfeit medicines that may be present in their selected sample of medicines. Such an approach would be beneficial in determining the type and prevalence rate of medicine quality problems in any setting and could consequently determine the most appropriate strategies to combat their threats.

\section{Acknowledgment}

AFAA is grateful to the Ministry of Higher Education in Saudi Arabia for sponsoring his $\mathrm{PhD}$ project.

\section{Disclosure}

The authors report no conflicts of interest in this work.

\section{References}

1. Waller P. Pharmacoepidemiology - a tool for public health. Pharmacoepidemiol Drug Saf. 2001;10(2):165-172.

2. Amin AA, Snow RW, Kokwaro GO. The quality of sulphadoxinepyrimethamine and amodiaquine products in the Kenyan retail sector. J Clin Pharm Ther. 2005;30(6):559-565.

3. World Health Organization. Counterfeit Drugs. Geneva: World Health Organization; 1999. Available from: http://whqlibdoc.who.int/hq/1999/ WHO_EDM_QSM_99.1.pdf. Accessed May 16, 2013.

4. World Health Organization. Substandard and Counterfeit Medicines. Geneva: World Health Organization; 2003. Available from http:// www.who.int/mediacentre/factsheets/2003/fs $275 /$ en/. Accessed May 10, 2012.

5. World Health Organization. What Are Substandard Medicines? Geneva: World Health Organization; 2014. Available from: http://www.who.int/ medicines/services/counterfeit/faqs/06/en/. Accessed February 8, 2014.

6. USP council of convention section on global public health; USP council of experts international health expert committee; USP regionalization team, Heyman ML, Williams RL. Ensuring global access to quality medicines: role of the US Pharmacopeia. J Pharm Sci. 2011;100(4):1280-1287.

7. Yankus W, Marks S. Counterfeit Drugs: Coming to a Pharmacy Near You with an Update for 2009. New York: American Council on Science and Health; 2009. Available from: http://acsh.org/2006/08/counterfeitdrugs-coming-to-a-pharmacy-near-you-2/. Accessed November 15, 2011.

8. Wertheimer AI, Norris J. Safeguarding against substandard/counterfeit drugs: mitigating a macroeconomic pandemic. Res Social Adm Pharm. 2009;5(1):4-16.

9. Clift C. Combating Counterfeit, Falsified and Substandard Medicines: Defining the Way Forward? London: Chatham House; 2010. Available from: http://www.chathamhouse.org/sites/default/files/public/Research/ Global\%20Health/1110bp_counterfeit.pdf. Accessed October 15, 2011.

10. Deats M, Bourdillon-Esteve P. Substandard, Spurious, Falsely Labelled, Falsified and Counterfeit (SSFFC) Medical Products: Global Surveillance and Monitoring Project. Geneva: World Health Organization; 2013. Available from: http://www.who.int/medicines/technical_briefing/tbs/ WHO_HQ_TBS_Oct_2013.pdf. Accessed February 8, 2014.

11. Newton PN, Lee SJ, Goodman C, et al. Guidelines for field surveys of the quality of medicines: a proposal. PLoS Med. 2009;6(3):e52.

12. Newton PN, Amin AA, Bird C, et al. The primacy of public health considerations in defining poor quality medicines. PLoS Med. 2011; 8(12):e1001139.

13. Amin AA, Kokwaro GO. Antimalarial drug quality in Africa. J Clin Pharm Ther. 2007;32(5):429-440.

14. World Health Organization. International Medical Products Anti-Counterfeiting Taskforce - IMPACT. Geneva, World Health Organization; 2011. Available from: http://www.who.int/impact/en/. Accessed February 8, 2014.

15. Cockburn R, Newton PN, Agyarko EK, Akunyili D, White NJ. The global threat of counterfeit drugs: why industry and governments must communicate the dangers. PLoS Med. 2005;2(4):e100.

16. Mackey TK, Liang BA. The global counterfeit drug trade: patient safety and public health risks. J Pharm Sci. 2011;100(11):4571-4579.

17. Kao SL, Chan CL, Tan B, et al. An unusual outbreak of hypoglycemia. N Engl J Med. 2009;360(7):734-736.

18. Lühn S, Schiemann S, Alban S. Simple fluorescence assay for quantification of OSCS in heparin. Anal Bioanal Chem. 2011;399(2): 673-680.

19. Davison M. Pharmaceutical Anti-Counterfeiting Combating the Real Danger from Fake Drugs. New Jersey: John Wiley \& Sons Inc.; 2011. 
20. Holzgrabe U, Malet-Martino M. Analytical challenges in drug counterfeiting and falsification - The NMR approach. J Pharm Biomed Anal. 2011;55(4):679-687.

21. Moken MC. Fake pharmaceuticals: how they and relevant legislation or lack thereof contribute to consistently high and increasing drug prices. Am J Law Med. 2003;29(4):525-542.

22. Ziance RJ. Roles for pharmacy in combatting counterfeit drugs. $J A m$ Pharm Assoc (2003). 2008;48(4):e71-e88.

23. Caudron JM, Ford N, Henkens M, Macé C, Kiddle-Monroe R, Pinel J. Substandard medicines in resource-poor settings: a problem that can no longer be ignored. Trop Med Int Health. 2008;13(8):1062-1072.

24. Fried M. Is this pill safe? Substandard medicines, mistaken solutions. CMAJ. 2011;183(8):984.

25. Newton PN, Green MD, Fernández FM, Day NPJ, White NJ. Counterfeit anti-infective drugs. Lancet Infect Dis. 2006;6(9):602-613.

26. Nayyar GML, Breman JG, Newton PN, Herrington J. Poor-quality antimalarial drugs in southeast Asia and sub-Saharan Africa. Lancet Infect Dis. 2012;12(6):488-496.

27. Kelesidis T, Kelesidis I, Rafailidis PI, Falagas ME. Counterfeit or substandard antimicrobial drugs: a review of the scientific evidence. J Antimicrob Chemother. 2007;60(2):214-236.

28. Almuzaini T, Choonara I, Sammons H. Substandard and counterfeit medicines: a systematic review of the literature. BMJ Open. 2013;3(8):e002923.

29. Moher D, Liberati A, Tetzlaff J, Altman DG, Group TP; PRISMA Group. Preferred reporting items for systematic reviews and metaanalyses: the PRISMA statement. PLoS Med. 2009;6(7):e1000097.

30. Bate R, Jensen P, Hess K, Mooney L, Milligan J. Substandard and falsified anti-tuberculosis drugs: a preliminary field analysis. Int J Tuberc Lung Dis. 2013;17(3):308-311.

31. Stanton C, Koski A, Cofie P, Mirzabagi E, Grady BL, Brooke S. Uterotonic drug quality: an assessment of the potency of injectable uterotonic drugs purchased by simulated clients in three districts in Ghana. BMJ Open. 2012;2(3):e000431.

32. Baratta F, Germano A, Brusa P. Diffusion of counterfeit drugs in developing countries and stability of galenics stored for months under different conditions of temperature and relative humidity. Croat Med J. 2012;53(2):173-184.

33. Nair A, Strauch S, Lauwo J, Jähnke RW, Dressman J. Are counterfeit or substandard anti-infective products the cause of treatment failure in Papua New Guinea? J Pharm Sci. 2011;100(11):5059-5068.

34. Ali SA, Ezika CC, Abdulraheem OR, et al. Quality assessment of Artemisinin-based drugs marketed and used in Maiduguri Metropolitan Council Borno State, Nigeria. Res J Pharm Biol Chem Sci. 2011;2(2):615-623.

35. Khan MH, Okumura J, Sovannarith T, Nivanna N, Akazawa M, Kimura K. Prevalence of counterfeit anthelminthic medicines: a cross-sectional survey in Cambodia. Trop Med Int Health. 2010;15(5): 639-644.

36. Ochekpe NA, Agbowuro AA, Attah SE. Correlation of price and quality of medicines: assessment of some artemisinin antimalarials in Nigeria based on GPHF minilab. Int J Drug Dev Res. 2010;2(1): 211-218.

37. Bate R, Tren R, Mooney L, et al. Pilot study of essential drug quality in two major cities in India. PLoS ONE. 2009;4(6):e6003.

38. Onwujekwe O, Kaur H, Dike N, et al. Quality of anti-malarial drugs provided by public and private healthcare providers in south-east Nigeria. Malar J. 2009;8(1):22.

39. Risha PG, Msuya Z, Clark M, Johnson K, Ndomondo-Sigonda M, Layloff $T$. The use of Minilabs to improve the testing capacity of regulatory authorities in resource limited settings: Tanzanian experience. Health Policy. 2008;87(2):217-222.

40. Tipke M, Diallo S, Coulibaly B, et al. Substandard anti-malarial drugs in Burkina Faso. Malar J. 2008;7(1):95.

41. Bate R, Coticelli P, Tren R, Attaran A. Antimalarial drug quality in the most severely malarious parts of Africa - a six country study. PLoS ONE. 2008;3(5):e2132.
42. Pouillot R, Bilong C, Boisier P, et al. Le circuit informel des médicaments à Yaoundé et à Niamey : étude de la population des vendeurs et de la qualité des médicaments distribués. [Illicit drug trade on the markets of Yaounde (Cameroon) and Niamey (Niger): characteristics of salesmen and quality of drugs]. Bull Soc Pathol Exot. 2008;101(2):113-118. French.

43. Ofori-Kwakye K, Asantewaa Y, Gaye O. Quality of artesunate tablets sold in pharmacies in Kumasi, Ghana. Trop J Pharm Res. 2008;7(4):1179-1184.

44. Atemnkeng MA, Chimanuka B, Plaizier-Vercammen J. Quality evaluation of chloroquine, quinine, sulfadoxine-pyrimethamine and proguanil formulations sold on the market in East Congo DR. J Clin Pharm Ther. 2007;32(2):123-132.

45. Gaudiano MC, Di Maggio A, Cocchieri E, et al. Medicines informal market in Congo, Burundi and Angola: counterfeit and sub-standard antimalarials. Malar J. 2007;6(1):22.

46. Atemnkeng MA, De Cock K, Plaizier-Vercammen J. Quality control of active ingredients in artemisinin-derivative antimalarials within Kenya and DR Congo. Trop Med Int Health. 2007;12(1):68-74.

47. Syhakhang L, Freudenthal S, Tomson G, Wahlström R. Knowledge and perceptions of drug quality among drug sellers and consumers in Lao PDR. Health Policy Plan. 2004;19(6):391-401.

48. Basco LK. Molecular epidemiology of malaria in Cameroon. XIX. Quality of antimalarial drugs used for self-medication. Am J Trop Med Hyg. 2004;70(3):245-250.

49. Dondorp AM, Newton PN, Mayxay M, et al. Fake antimalarials in Southeast Asia are a major impediment to malaria control: multinational cross-sectional survey on the prevalence of fake antimalarials. Trop Med Int Health. 2004;9(12):1241-1246.

50. Prazuck T, Falconi I, Morineau G, Bricard-Pacaud V, Lecomte A, Ballereau F. Quality control of antibiotics before the implementation of an STD program in Northern Myanmar. Sex Transm Dis. 2002;29(11):624-627.

51. Taylor RB, Shakoor O, Behrens RH, et al. Pharmacopoeial quality of drugs supplied by Nigerian pharmacies. Lancet. 2001;357(9272): 1933-1936.

52. Stenson B, Lindgren BH, Syhakhang L, Tomson G. The quality of drugs in private pharmacies in the Lao People's Democratic Republic. Int $J$ Risk Saf Med. 1998;11(4):243-249.

53. Shakoor O, Taylor RB, Behrens RH. Assessment of the incidence of substandard drugs in developing countries. Trop Med Int Health. 1997;2(9):839-845.

54. Dorlo TP, Eggelte TA, de Vries PJ, Beijnen JH. Characterization and identification of suspected counterfeit miltefosine capsules. Analyst (Lond). 2012;137(5):1265-1274.

55. Sengaloundeth S, Green MD, Fernández FM, et al. A stratified random survey of the proportion of poor quality oral artesunate sold at medicine outlets in the Lao PDR - implications for therapeutic failure and drug resistance. Malar J. 2009;8(1):172.

56. Newton PN, Fernández FM, Plançon A, et al. A collaborative epidemiological investigation into the criminal fake artesunate trade in South East Asia. PLoS Med. 2008;5(2):e32.

57. Newton P, Proux S, Green M, et al. Fake artesunate in southeast Asia. Lancet. 2001;357(9272):1948-1950.

58. Said MM, Gibbons S, Moffat AC, Zloh M. Near-infrared spectroscopy (NIRS) and chemometric analysis of Malaysian and UK paracetamol tablets: a spectral database study. Int J Pharm. 2011;415(1-2): 102-109.

59. Haruna B, Adaku OE, Usifoh CO. Chemical equivalence study on four brands of $\alpha$-methyldopa. J Chem Pharm Res. 2013;5(10):356-358.

60. Audu SA, Taiwo AE, Saidu KO, et al. Quantitative analysis of ten (10) different brands of chlorpheniramine tablet marketed in Maiduguri metropolitan council (MMC). J Chem Pharm Res. 2012;4(7): 3637-3650.

61. Ramachandran G, Chandrasekaran V, Hemanth Kumar AK, Dewan P, Swaminathan S, Thomas A. Estimation of content of anti-TB drugs supplied at centres of the Revised National TB Control Programme in Tamil Nadu, India. Trop Med Int Health. 2013;18(9):1141-1144. 
62. Khan MH, Hatanaka K, Sovannarith T, et al. Effects of packaging and storage conditions on the quality of amoxicillin-clavulanic acid An analysis of Cambodian samples. BMC Pharmacol Toxicol. 2013;14:33.

63. Affum AO, Lowor S, Osae SD, Dickson A, Gyan BA, Tulasi D. A pilot study on quality of artesunate and amodiaquine tablets used in the fishing community of Tema, Ghana. Malar J. 2013; 12(1):220.

64. Briesen S, Guthoff R, Kilangalanga N, Mundkowski RG. Counterfeiting von Augentropfen?: Eine Untersuchung von Antibiotikapräparaten aus 2 Ländern Afrikas. [Counterfeiting of eye drops?: a laboratory study of antibiotic eye drops purchased in two African countries] Ophthalmologe. 2012;109(12):1207-1210. German.

65. Nogueira FH, Moreira-Campos LM, Santos RL, Pianetti GA. Quality of essential drugs in tropical countries: evaluation of antimalarial drugs in the Brazilian Health System. Rev Soc Bras Med Trop. 2011;44(5):582-586

66. El-Duah M, Ofori-Kwakye K. Substandard artemisinin-based antimalarial medicines in licensed retail pharmaceutical outlets in Ghana. J Vector Borne Dis. 2012;49(3):131-139.

67. Karlage KL, Franklin SJ, Mufich WC, et al. Comparative evaluation of pharmaceutical products obtained in Mexico: augmenting existing scientific data. Drug Dev Ind Pharm. 2012;38(7):808-814.

68. Pribluda VS, Barojas A, Añez A, et al. Implementation of basic quality control tests for malaria medicines in Amazon Basin countries: results for the 2005-2010 period. Malar J. 2012;11(1):202.

69. Klein EY, Lewis IA, Jung C, Llinás M, Levin SA. Relationship between treatment-seeking behaviour and artemisinin drug quality in Ghana. Malar J. 2012;11(1):110.

70. Ehianeta T, Williams B, Surakat J, Mohammed N, Anyakora C. Quality survey of some brands of artesunate-amodiaquine in Lagos drug market. Afr J Pharm Pharmacol. 2012;6:636-642.

71. Bate R, Jin GZ, Mathur A. Does price reveal poor-quality drugs? Evidence from 17 countries. J Health Econ. 2011;30(6) $1150-1163$.

72. Seear M, Gandhi D, Carr R, Dayal A, Raghavan D, Sharma N. The need for better data about counterfeit drugs in developing countries: a proposed standard research methodology tested in Chennai, India J Clin Pharm Ther. 2011;36(4):488-495.

73. Akpabio E, Jackson C, Ugwu C, Etim M, Udofia M. Quality control and in vitro bioequivalence studies on four brands of ciprofloxacin tablets commonly sold in Uyo Metropolis, Nigeria. J Chem Pharm Res. 2011;3(3):734-741.

74. Hadi U, van den Broek P, Kolopaking EP, Zairina N, Gardjito W, Gyssens IC; Study Group Antimicrobial Resistance in Indonesia: Prevalence and Prevention AMRIN. Cross-sectional study of availability and pharmaceutical quality of antibiotics requested with or without prescription (Over The Counter) in Surabaya, Indonesia. BMC Infect Dis. 2010;10(1):203.

75. Bate R, Hess K. Anti-malarial drug quality in Lagos and Accra - A comparison of various quality assessments. Malar J. 2010;9(1):157.

76. Leslie T, Kaur H, Mohammed N, Kolaczinski K, Ord RL, Rowland M. Epidemic of Plasmodium falciparum malaria involving substandard antimalarial drugs, Pakistan, 2003. Emerg Infect Dis. 2009;15(11):1753-1759.

77. Twagirumukiza M, Cosijns A, Pringels E, Remon JP, Vervaet C, Van Bortel L. Influence of tropical climate conditions on the quality of antihypertensive drugs from Rwandan pharmacies. Am J Trop Med Hyg. 2009;81(5):776-781.

78. Obaid A. Quality of ceftriaxone in Pakistan: reality and resonance. Pak J Pharm Sci. 2009;22(2):220-229.

79. Bate R, Tren R, Hess K, Mooney L, Porter K. Pilot study comparing technologies to test for substandard drugs in field settings. African Journal of Pharmacy and Pharmacology. 2009;3(4):165-170.

80. Fotiou F, Aravind S, Wang PP, Nerapusee O. Impact of illegal trade on the quality of epoetin alfa in Thailand. Clin Ther. 2009;31(2): 336-346.
81. Kaur H, Goodman C, Thompson E, et al. A nationwide survey of the quality of antimalarials in retail outlets in Tanzania. PLoS ONE. 2008;3(10):e3403.

82. Kyriacos S, Mroueh M, Chahine RP, Khouzam O. Quality of amoxicillin formulations in some Arab countries. J Clin Pharm Ther. 2008;33(4):375-379.

83. Meos A, Paap M, Matto V, Veski P. Comparative evaluation of quality of doxycycline formulations registered in Estonia to those registered in the Russian Federation. Drug Dev Res. 2008;69(2):58-68.

84. Bronnikova O, Matto V, Meos A. Comparative study of amoxicillin formulations registered in Estonia to those produced in Russia. Eur $J$ Pharm Sci. 2007;32(Suppl 1):S50.

85. Vijaykadga S, Cholpol S, Sitthimongkol S, et al. Strengthening of national capacity in implementation of antimalarial drug quality assurance in Thailand. Southeast Asian J Trop Med Public Health. 2006;37(3) (Suppl 3):5-10.

86. Lon CT, Tsuyuoka R, Phanouvong S, et al. Counterfeit and substandard antimalarial drugs in Cambodia. Trans $R$ Soc Trop Med Hyg 2006;100(11):1019-1024.

87. Abdo-Rabbo A, Bassili A, Atta H. The quality of antimalarials available in Yemen. Malar J. 2005;4(1):28.

88. Rookkapan K, Chongsuvivatwong V, Kasiwong S, Pariyawatee S, Kasetcharoen Y, Pungrassami P. Deteriorated tuberculosis drugs and management system problems in lower southern Thailand. Int J Tuberc Lung Dis. 2005;9(6):654-660.

89. Kayumba PC, Risha PG, Shewiyo D, et al. The quality of essential antimicrobial and antimalarial drugs marketed in Rwanda and Tanzania: influence of tropical storage conditions on in vitro dissolution. J Clin Pharm Ther. 2004;29(4):331-338

90. Minzi OMS, Moshi MJ, Hipolite D, et al. Evaluation of the quality of amodiaquine and sulphadoxine/pyrimethamine tablets sold by private wholesale pharmacies in Dar Es Salaam Tanzania. J Clin Pharm Ther. 2003;28(2):117-122.

91. Obodozie OO, Mustapha KB, Ebeshi BU, Inyang US. A comparative study on the prevalence of substandard ampicillin/cloxacillin preparations in the Nigerian market: Mid 1990's and present. J Phytomed Therapeutics. 2006;11:1-8.

92. Laserson KF, Kenyon AS, Kenyon TA, Layloff T, Binkin NJ. Substandard tuberculosis drugs on the global market and their simple detection. Int J Tuberc Lung Dis. 2001;5(5):448-454.

93. Kenyon TA, Kenyon AS, Kgarebe BV, Mothibedi D, Binkin NJ, Layloff TP. Detection of substandard fixed-dose combination tuberculosis drugs using thin-layer chromatography. Int J Tuberc Lung Dis. 1999;3(11)(suppl 3):S347-S350, discussion S351-S352.

94. World Health Organization. Assessment of Medicines Regulatory Systems in Sub-Saharan African Countries: An Overview of Findings from 26 Assessment Reports. Geneva: World Health Organization; 2010. Available from: http://apps.who.int/medicinedocs/documents/ s17577en/s17577en.pdf. Accessed January 3, 2014

95. McGinnis M. Media Reports on Medicine Quality: Focusing on USAIDAssisted Countries. Rockville, MD: United States Pharmacopeia; 2013. Available from: http://www.usp.org/sites/default/files/usp_pdf/EN/ media_reports-2013-october.pdf. Accessed January 4, 2014.

96. World Health Organization. Report of the Situation of Counterfeit Medicines Based on Data Collection Tool: WHO Regions for Africa and Eastern Mediterranean. Geneva: World Health Organization; 2010. Available from: http://www.who.int/medicines/services/expertcommittees/pharmprep/WHO-ACM-3IMPACTSurveyDataCollectionToolReport.pdf. Accessed January 3, 2014.

97. World Health Organization. Noncommunicable Diseases. Geneva: World Health Organization; 2013. Available from: http://www. who.int/mediacentre/factsheets/fs355/en/. Accessed July 31, 2013.

98. World Health Organization. Contaminated Isotab ${ }^{\circledR}$ (Isosorbide Mononitrate) Incident in Lahore Pakistan. Geneva: World Health Organization; 2012. Available from: http://www.who.int/medicines/publications/ drugalerts/DrugSafetyAlert125.pdf. Accessed August 28, 2013. 
99. Nishtar S. Pakistan's deadly cocktail of substandard drugs. Lancet. 2012;379(9821):1084-1085.

100. US Food and Drug Administration. Avastin (bevacizumab): Counterfeit Product-FDA Issues Letters to 19 Medical Practices. Washington, DC: US Food and Drug Administration; 2012. Available from: http:// www.fda.gov/safety/medwatch/safetyinformation/safetyalertsforhum anmedicalproducts/ucm291968.htm. Accessed January 4, 2014.

101. US Food and Drug Administration. Altuzan (bevacizumab): Counterfeit Product-Contains No Active Ingredient. Washington, DC: US Food and Drug Administration; 2012. Available from: http://www.fda.gov/ safety/medwatch/safetyinformation/safetyalertsforhumanmedicalproducts/ucm298583.htm. Accessed January 4, 2014.

102. World Health Organization. Medicines: Spurious/Falsely-Labelled/ Falsified/Counterfeit (SFFC) Medicines. Geneva: World Health Organization; 2012. Available from: http://www.who.int/mediacentre/ factsheets/fs275/en/. Accessed July 20, 2013.
103. Lung DD, Gerona RR, Wu AH, Smollin CG. Confirmed glyburide poisoning from ingestion of "street Valium". J Emerg Med. 2012;43(2):276-278.

104. International Pharmaceutical Federation. Tool for Visual Inspection of Medicines. The Hague: International Pharmaceutical Federation; 2013. Available from: https://www.fip.org/files/fip/counterfeit/ VisualInspection/A\%20tool\%20for\%20visual\%20inspection\%20 of\%20medicines\%20EN.pdf. Accessed: May 25, 2013.

105. Pharmaceutical Security Institute. Incident Trends. Vienna, VA, USA: Pharmaceutical Security Institute; 2012. Available from: http://www. psi-inc.org/incidentTrends.cfm. Retrieved April 14, 2012.

106. Gebran N, Al Haidari K. Assessment of prescribing information for generic drugs manufactured in the Middle East and marketed in Saudi Arabia. Ann Saudi Med. 2006;26(3):192-199.

107. Al-Aqeel SA. Evaluation of medication package inserts in Saudi Arabia. Drug Healthc Patient Saf. 2012;4:33-38.

\section{Publish your work in this journal}

Integrated Pharmacy Research and Practice is an international, peer-reviewed, open access, online journal, publishing original research, reports, reviews and commentaries on all areas of academic and professional pharmacy practice. This journal aims to represent the academic output of pharmacists and pharmacy practice with particular focus on integrated care. All papers are carefully peer reviewed to ensure the highest standards as well as ensuring that we are informing and stimulating pharmaceutical professionals. The manuscript management system is completely online and includes a very quick and fair peer-review system, which is all easy to use. Visit http://www.dovepress.com/testimonials.php to read real quotes from published authors.

Submit your manuscript here: http://www.dovepress.com/integrated-pharmacy-research-and-practice-journal 